\title{
Evaluation of clinical response and efficiency of laser treatment for removing or significantly improving in facial nevi in north Indian population
}

\author{
Anil Rajput ${ }^{1, *}$, Rakesh Bansal ${ }^{2}$, Ragini Sengar ${ }^{3}$, Piyush Chaudhary ${ }^{4}$ \\ ${ }^{1} \mathrm{HOD},{ }^{2}$ Skin Specialist, ${ }^{3} \mathrm{Clinical}$ and Laser Assistant, ${ }^{4}$ Junior Resident, Dept. of Plastic Surgery, ${ }^{1,3,4}$ Teerthanker Mahaveer \\ University, Moradabad, Uttar Pradesh, LCSC Rajasthan, India
}

*Corresponding Author:

Email: dranilr.medical@tmu.ac.in

\begin{abstract}
Introduction: Melanocytic nevus is commonly occurring condition in Indian subjects. We investigate the clinical response and efficiency of laser for removing facial melanocytic nevi.

Materials and Methods: The present study comprised 98 patients in which 52 are females and 46 are males with age 12 to 57 years. These patients with different Nevus were treated with different laser for a period of 38 months. Patients had skin types 4 and 5 and 6 based on fitzpatrick skin type. The results were documented and clinical photographs were taken before and after completion of treatments.

Results: good-to-excellent results were presented by $96 \%$ patients. All subjects completed the study and the follow-up visits. Treatment was well tolerated overall by all participants, with no major adverse events. Out of 98 patients 20 patients received one or two session of treatment in which 10 were received very satisfactory result, 6 patients received good result and 3 received fair result. Out of 98 patients 38 patients had $95 \%$ clearance and 24 had $90 \%$ clearance of nevi with treatment sessions ranging from 3-8.

Conclusion: we recommend that in cases of nevus in Indian patients, Q-switched Nd: YAG, Er: YAG, Intensive Pulsed Laser (IPL) and Pulsed Dye Laser (PDL) are easy-to perform, safe and effective treatment. Good results were taken after laser treatment on nevi, on an average $96 \%$ of the patients received good-to-excellent results.
\end{abstract}

Keywords: Q-switched Nd: YAG laser, Er: YAG, Pulsed dye laser, Intensive pulsed laser facial nevus, Melanocytic nevi.

\section{Introduction}

Melanocytic nevi is commonly occuring condition in Indian subjects and having incidence of one in 1000 birth. A congenital melanocytic nevus present at birth or develop shortly after birth as a proliferation of benign melanocytes (pigment cells). ${ }^{1}$ Melanocytic nevi are very common and usually harmless. Most melanocytic nevi are noticeable in initial childhood and reach maximal size in young adolescence, while some may arise in adulthood. Depending on the size and location, the presence of such lesions may cause great anxiety in a parent, who may seek medical attention for the affected child. Some nevi carry malignant potential or are part of a syndrome. Others are quite disfiguring and are a source of psychosocial impairment. The wide range of population require no treatment. Due to cosmetic reasons some people may desire nevi ejection, particularly when they are present on the face, arms, hands and legs or any exposed area. Since the cure of nevi is often done for cosmetic basis, it must not only be effective but risk free also and is execute in well mannerly so the imperession of adverse sequelae is reduce as much as likely. Electrocauterization, surgical excision, radio-frequency, cryotherapy or electrodessication, and carbon dioxide laser, these are the different methods to treat Melanocytic nevus. Anew and repeated $\mathrm{CO} 2$ and Er: YAG laser therapies have been used due to their very simple administering and expertise to treat multiple lesions in due time. The optimal cosmetic results are maximizes by these assistance. $^{2,3}$ However, post-operative scarring and pigmentary changes in the procedure site may cause by the $\mathrm{CO} 2$ laser. Additionally, the use of pigments pacific lasers, such as the Q-switched ruby laser and Qswitched alexandrite laser, may lead to an insufficient excision of nevus cells. The Q-switched Nd: YAG laser is capable of penetrating into the deeper regions of the skin due to near infrared ray of $1,064 \mathrm{~nm}$. So, it is capable to destroy deep-seated dermal melanocytes by elective photothermolysis. ${ }^{4}$ Due to this intention, many hospitals and clinics usually use this laser to treat nevus.

In 1960 Leon Goldman was first to adopt the Ruby laser for benign pigmented lesions, Later in 1983, Anderson and Parrish's theory of selective photo thermolysis revolutionized laser therapy. ${ }^{5}$ The chromophore targeted by the laser in this context is melanin. Melanosomes are 0.5 micrometers in size whereas a nevus cell is 10 micrometers in size. The pulses of light required to treat non-malignant melanocytic nevi must be very short as per the concept of thermal relaxation time (TRT), to minimize collateral thermal injury to the normal surrounding tissue. ${ }^{6}$ As the thermal relaxation time of a melanosome is 0.25 microsecond and that of a nevus cell is 0.1 millisecond, lasers with pulse duration in the nanosecond range are used. ${ }^{6}$ A laser of $1064 \mathrm{~nm}$ wavelength penetrates up to 2-3 $\mathrm{mm}$, thus ensuring adequate dermal penetration. ${ }^{7}$ So we investigate the clinical response and efficiency of laser for removing facial nevi, including congenital melanocytic and acquired melanocytic nevi. 


\section{Materials and Methods}

The present study comprised 98 patients in which 52 are females and 46 are males with age 12 to 57 years who were treated in department of plastic surgery of Teerthanker Mahaveer Medical College, research centre and hospital. Written consent forms were taken from every individual. These patients with different Nevus were treated with Q-switched Nd: YAG (Neodymiumdoped yttrium aluminum garnet laser), Er: YAG (Erbium-doped yttrium aluminum garnet laser) and IPL ( Intensive pulsed laser) for a period of 38 months. The including Patients had skin types 4 and 5 and 6 based on Fitzpatrick skin type. The results were documented and clinical photographs were taken before and after completion of treatments. One-month follow-up was done after the last session. Response to treatment was graded based on physician's global assessment. Skin biopsy was not performed in routine, but in case of doubt for involvement of deep dermis by melanocytes, and clinical signs of malignancy. In this study, skin biopsy was performed for microscopic view of melanocyte's position and concentration of cells in 3 patients from non-exposed part of nevi. Topical anesthesia (lidocaine and prilocaine combination) was applied and Local infiltration anesthesia with $2 \%$ xylocaine was used in patients having large nevi. Patients' eyes were covered with protective shields. laser parameters were used: Q-switched Nd: YAG laser of $1064 \mathrm{~nm}$ wavelength, Er: YAG laser with a wavelength of $2940 \mathrm{~nm}$ were used, and if any hypertrophy occur than we have gone for pulsed dye laser (595nm wavelength in V beam) and intra-lesional steroid injections. Non-malignant melanocytic nevi are small lesions and one has better control while treating them with a repetition rate of 2 and $5 \mathrm{~Hz} .1064 \mathrm{~nm}$ was used to remove the pigment at dermal level (darker speckles) and $532 \mathrm{~nm}$ to remove basilar pigmentation. All these wavelengths can effectively treat pigmented lesions without disrupting the normal surrounding tissue. Q switched systems emitting longer wavelengths $(694,755,1064 \mathrm{~nm})$ can eliminate deep dermal melanin. A combination of IPL and Nd: YAG were find a safer and more effective treatment for congenital melanocytic nevi because of short recovery time, minimal scarring and short procedure time. Evaluation of results was made on visual inspection and by comparing serial photographs for reduction of pigment and size of lesion using subjective grading score. After the laser treatment, an antibiotic dressing was given for 7-10 days along with analgesics, as needed, to control the pain until the wound had healed. The statistical analysis was done with the help of Microsoft office excel 2007.

\section{Results}

This study included 98 patients in which 52 females and 46 Are males; aged 12 to 57 years; mean age, 25.5 years. Multiple nevi could be treated in a short time. The number of patients by section of face was as follows:

\section{Site of major nevus:}

1. Congenital Melanocytic nevi extending from root of nose to upper lip inferiorly and on right side zygomatic arch laterally and up to zygoma on left side. (Fig. 1)

2. Nevus of Ota Extending from supra orbital margin, infra orbital margin, zygoma and whole of right cheek (Fig. 2)

3. Dermal nevus on tip of nose and left cheek. (Fig. 3)

4. Nevus sebaceous from medial surface of external ear extending up to suboccipital region. (Fig. 4)
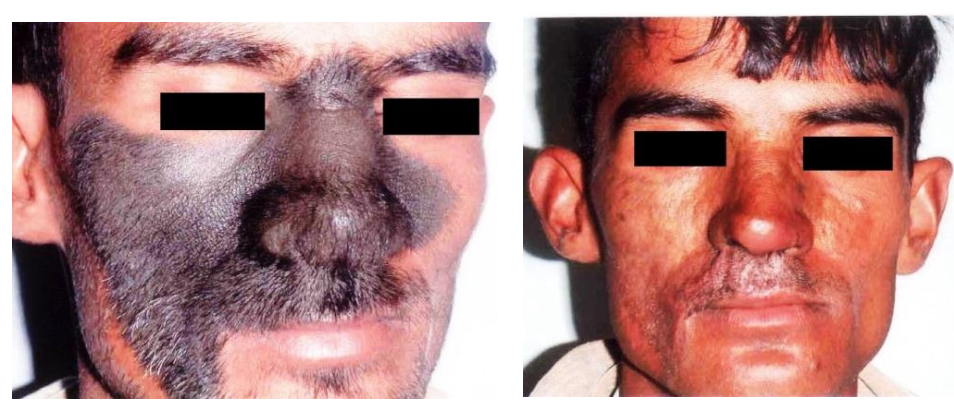

Fig. 1: Pre and post treatment photograph of congenital melanocytic nivus
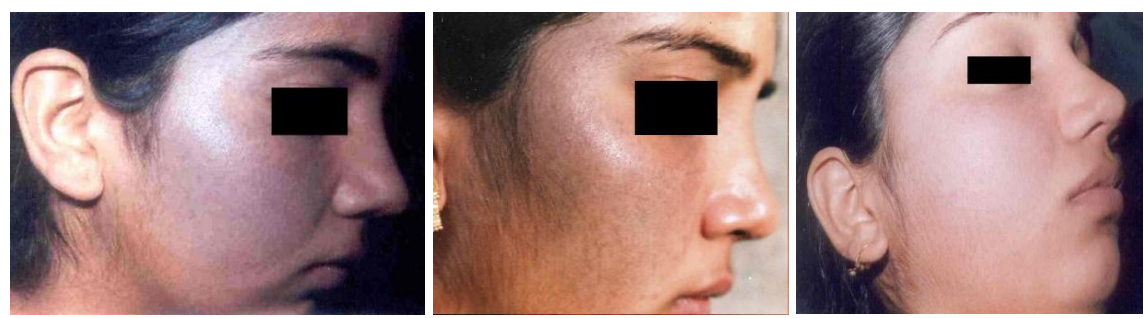

Fig. 2: Pre, intermediate and post treatment result of nevus of Ota 


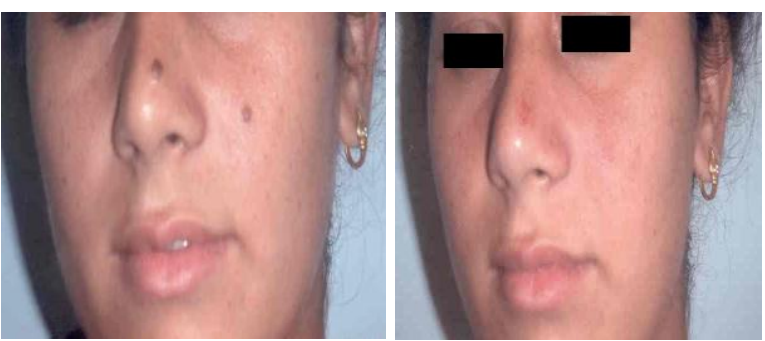

Fig. 3: Pre and post treatment photograph of dermal nevus
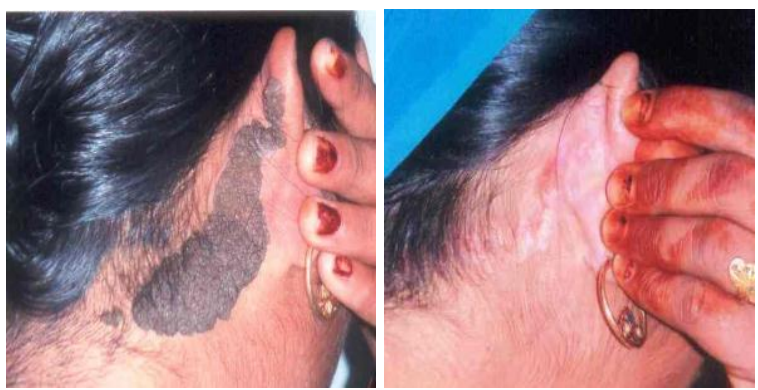

Fig. 4: Pre and post treatment photograph of nevus sebaceous

In 98 patients, $96 \%$ of the patients received good to excellent results after laser treatment. In which 20 patients attend one to two session and did not require additional session. All subjects completed the study and the follow-up visits. Treatment was well tolerated overall by all participants, with no major adverse events.

Out of 98 patients 20 patients received one to two sessions of treatment in which 10 were received very satisfactory result, 6 patients received good result and 3 received fair result. Fig. 1 to 4 demonstrates the clinical results seen in the patients. Out of 98 patients 38 patients had $95 \%$ clearance and 24 had $90 \%$ clearance of nevi with treatment sessions ranging from 3-8. Sixteen patients had good to excellent result after more than 8 treatments (Table 1, Graph 1,2). Patients of Nevus of Ota were treated with Q-switched ND: YAG laser which is requiring more than 8 treatments to achieve good cosmetic results. A direct correlation was observed between the number of sessions and reduction inpigment. 10 patients had recurrence and hypertrophy, in which recurrence was in 4 patients which recovered by reconstructive surgical methods and hypertrophy was in 6 patients which was recovered by intra-lesional steroid injection and Pulsed Dye Laser (PDL). (Table 2, Graph 3)

Table 1: Description of improvement in patients with number of treatment

\begin{tabular}{|c|c|c|c|c|c|}
\hline Number of treatment & Number of patients & \multicolumn{4}{|c|}{ Improvement (\%) } \\
\cline { 3 - 6 } & $(\boldsymbol{\%})$ & Excellent & Good & Fair & Poor \\
\hline $1-2$ & $20(20.4 \%)$ & 10 & 6 & 3 & 1 \\
\hline $3-8$ & $62(63.3 \%)$ & 38 & 24 & - & - \\
\hline$>8$ & $16(16.3 \%)$ & 13 & 3 & - & - \\
\hline Total & $98(100 \%)$ & $61(62.3 \%)$ & $33(33.7 \%)$ & $3(3 \%)$ & $1(1 \%)$ \\
\hline
\end{tabular}

\section{Graph 1: Description of patients with number of} treatment

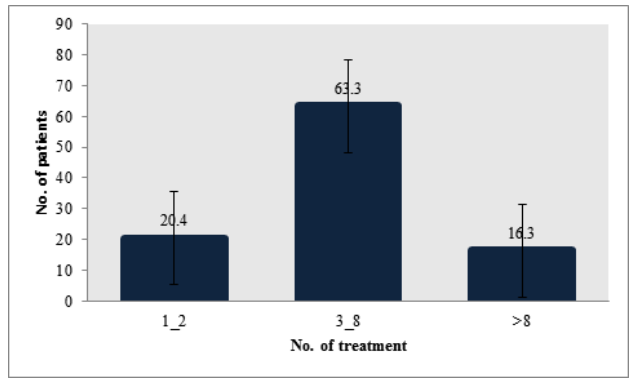

Graph 2: Improvement in total number of patients

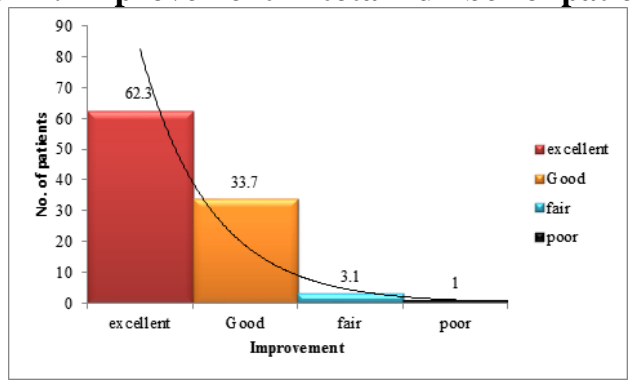


Table 2: Complications after treatment with its treatment methodology

\begin{tabular}{|l|c|c|}
\hline $\begin{array}{l}\text { Complications } \\
\text { after treatment }\end{array}$ & $\begin{array}{c}\text { Number of } \\
\text { patients } \\
(\%)\end{array}$ & $\begin{array}{c}\text { Method of } \\
\text { Treatment }\end{array}$ \\
\hline Recurrence & $4(4.1 \%)$ & $\begin{array}{c}\text { reconstructive } \\
\text { surgical methods }\end{array}$ \\
\hline Hypertrophy & $6(6.1)$ & $\begin{array}{c}\text { intra-lesional } \\
\text { steroid injection } \\
\text { and Pulsed Dye } \\
\text { Laser (PDL) }\end{array}$ \\
\hline
\end{tabular}

Graph 3: Complications after treatment

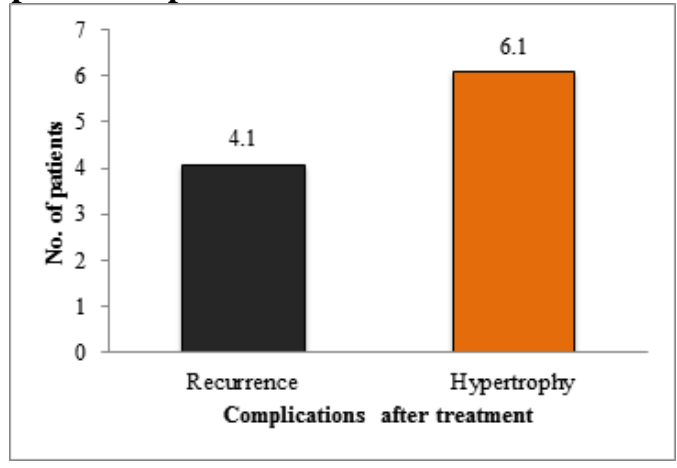

\section{Discussion}

The high energy is delivered in a very short time by the laser leading to rapid thermal expansion of the target to produce the desired effect and it also produces an additional photo acoustic effect. ${ }^{8}$ Melanocytic nevi respond expertly to Q-switched (QS) lasers which generate ultra-short bursts of laser light to target melanin in the melanocytes. Ruby $694 \mathrm{~nm}$, Alexendrite $755 \mathrm{~nm}$, and Nd: YAG laser $1064 \mathrm{~nm}$ these Q-switched lasers are available. The last one is applicable for the treatment of darker skin types as it reduce the risk of epidermal injury and pigmentary alteration. ${ }^{9,10}$ This wavelength has a deeper penetration into the dermis and is weakly absorbed by epidermal melanin, thus ideal to treat skin types 4-6. A combination of IPL and Nd: YAG were obtain a risk free and more proficient treatment for congenital melanocytic nevi because of minimal scarring short recovery and short procedure time. ${ }^{11}$ The treatment of congenital melanocytic nevi is controversial because of the maximum number of pigment cells are present, and lasers may not destroy all melanocytes especially those in deeper layers. ${ }^{12}$ It is also possible that removal of nevi, even partial, minimise the number of melanocytes and may decrease the potential of malignant change., Melanocytic nevi have been inadvertently lased during treatments for other conditions In the past, but malignant transformation has never been noticed. ${ }^{8}$

With a wavelength of $2940 \mathrm{~nm}$, Er: YAG lasers allow extremely precise skin ablation. It is efficiently absorbed by water and can be applied to produce minimal thermal injury, therefore, it can be used as perfect tool for cure superficial skin lesions. ${ }^{13-15} \mathrm{Er}$ : YAG laser resurfacing is an effective method of ablating congenital melanocytic nevi, with postoperative complications and minimal scarring.

However, due to the low level of tissue destruction and shortly traumatic procedure, there are many benefits of apply Er: YAG laser resurfacing in the treatment of a wide range of superficial skin lesions, such as swelling, minimal postoperative pain, necrosis, lack of local infections or unacceptable scarring. We thought that, this minimally traumatic technique is significantly advantageous in relation to the other comparable techniques (electrocautery, fulguration, $\mathrm{CO} 2$ laser etc.). Er: YAG lasers, with a wavelength of $2940 \mathrm{~nm}$, allow for extremely precise skin ablation. Their energy is very efficiently absorbed by water and can be used to produce a minimal thermal injury to approximately 5 to 10 micrometers. Therefore they can be considered as the absolute tool for treating superficial skin lesions. ${ }^{15}$

Q switched (QS) lasers have changed the management of pigmentary lesions to a great extent. Q stands for quality. ${ }^{16} \mathrm{Q}$ switching is a means of shuttering the laser output so that it is delivered in extremely short pulses of high intensity radiation. Lasers are monochromatic electromagnetic radiation source used to treat various skin disorders. Anderson and Parrish theory of selective photo-thermolysis states that the laser light must be of wavelength that is well absorbed by the target chromophore (absorption spectrum from 250 to $1200 \mathrm{~nm}$ ) and not the surrounding structures, the pulse duration should be less than or equal to the thermal relaxation time of the target to avoid collateral thermal damage, and finally sufficient fluence should be used to produce the desired effect. ${ }^{17-19} 10$ patients had recurrence and hypertrophy, in which recurrence was in 4 patients which was recovered by reconstructive surgical methods and hypertrophy was in 6 patients which was recovered by intra-lesional steroid injection and Pulsed Dye Laser (PDL).

In a study by Teekhasaenee et al., ${ }^{17} 59.3 \%$ had ocular and dermal involvement, while $35 \%$ had dermal involvement. Of the nine cases with ocular involvement, all had episcleral involvement, while three (33.3\%) each had involvement of the palpebral conjunctiva and the retina. Teekhasaenee et $\mathrm{al}^{20}$ reported $100 \%$ episcleral involvement, $10 \%$ conjunctival involvement, and $18 \%$ retinal involvement. Glaucoma was observed in a case of bilateral Nevus of Ota, Foulks and Shields ${ }^{21}$ and Khawly et $\mathrm{al}^{22}$ have reported this association. There have been previous studies in which Q switched lasers have been used for treating nevus of Ota. Geronemus ${ }^{23}$ treated 15 patients with QS ruby laser with greater than $50 \%$ clearing in all cases. The efficacy of QS ruby laser was later confirmed in another study involving 114 patients who demonstrated good clinical results with few side 
effects. ${ }^{23}$ Later, QS Nd: YAG and QS Alexandrite were used successfully to treat this condition. ${ }^{25}$

\section{Conclusion}

We recommend that in cases of nevus in Indian patients, Q-switched Nd: YAG, Er: YAG, Intensive Pulsed Laser (IPL) and Pulsed Dye Laser (PDL) are easy-to perform, safe and effective treatment. Good results were taken after laser treatment on nevi, on an average $96 \%$ of the patients received good-to-excellent results. All subjects completed the study and the follow-up visits. Treatment was well tolerated overall by all participants, with no major adverse events. Out of 98 patients 20 patients received one to two sessions of treatment in which 10 were received very satisfactory result, 6 patients received good result and 3 received fair result. Out of 98 patients 38 patients had 95\% clearance and 24 had $90 \%$ clearance of nevi with treatment sessions ranging from 3-8.

\section{References}

1. Viana ACL, Gontijo B, Bittencourt FV. Giant congenital melanocytic nevus. An Bras Dermatol. 2013;88(6): 86378.

2. Stratigos AJ, Dover JS, Arndt KA. Laser treatment of pigmentedlesions--2000: how far have we gone? Arch Dermatol2000;136:915-921.

3. Alster TS, Lupton JR. Laser therapy for cutaneous hyperpigmentation and pigmented lesions. Dermatol Ther 2001;14:46-54.

4. Anderson RR, Parrish JA. Selective photothermolysis: precise microsurgery by selective absorption of pulsed radiation. Science 1983;220:524-527.

5. Railan D, Kilmer S. Laser treatment of benign pigmented cutaneouslesions. In: Goldman MP, editor. Cutaneous and Cosmetic Laser Surgery. California: Elsevier Mosby; 2006. p.93-106.

6. Ross EV, Anderson RR. Laser-tissue interactions. In: Goldman MP, editor. Cutaneous and Cosmetic Laser Surgery. California: Elsevier Mosby;2006. p.1-26.

7. Pigmented lesions and tattoos. In: Goldberg DJ, editor. Lasers and Lights (Volume 1). Michigan: Elsevier Saunders; 2005. p.41-66.

8. Anderson RR, Parish JA. Selective Photothermolysis: Precise microsurgery by selective absorption of pulsed radiation. Science 1983;220:524-7.

9. Kilmer SL, Anderson RR. Clinical uses of Q-switched ruby and Q-switched Nd:YAG lasers for treatment of tattoos. J Dermatol Surg Oncol 1993;19:330-8.

10. Grevelink JM, Duke D, Van Leeuwen RL, Gonzalez E, De Coste SD, Anderson RR. Laser treatment of tattoos in darkly pigmented patients: Efficacy and side effects. J Am Acad Dermatol 1996;34:653-6.

11. Hoonhur, Chan Hyuk Park, Yu Ri Kim, Pyoung Su Kim. Treatment of congenital melanocytic nevus by new combination therapy: intense pulsed light therapy and Dr.hoonhur's golden parameter therapy. Jdermat and therapies (JDT) 2017;1(1):12-16.

12. Grevelink JM, van Leeuwen RL, Gonzalez E, Anderson RR, Byers HR. Clinical and histological responses of congenital melanocytic nevi after single treatment with Q-switched lasers. Arch Dermatol 1997;133:349-53.
13. Bass LS. Erbium: YAG laser skin resurfacing: preliminary clinical evaluation. Ann Plast Surg. Apr 1998;40(4):328-34

14. Kaufmann R, Hibst R. Pulsed 2.94-microns erbium-YAG laser skin ablation: experimental results and first clinical application. Clin Exp Dermatol 1990;15:389-93.

15. Park JH, Hwang ES, Kim SN, Kye YC. Er: YAG laser treatment of verrucous epidermal nevi. Dermatol Surg. 2004 Mar;30(3):378-81.

16. Kilmer SL, Garden JM. Laser treatment of pigmented lesions and tattoos (review). Semin Cutan Med Surg 2000;19:232-44.

17. Anderson RR, Parrish JA. Selective photothermolysis: Precisemicrosurgery by selective absorption of pulsed radiation. Science 1983;220:524.

18. Anderson RR, Margolis RJ, Watanabe S, Flotte T, Hruza GJ, DoverJS. Selective photothermolysis of cutaneous pigmentation by Qswitched Nd: YAG laser pulses at 1064nm, 532nm, 355nm. JInvest Dermatol 1989;93:2832.

19. Dover JS, Margolis RJ, Polla LL, Watanabe S, Hruza GJ, Parrish JA, et al. Pigmented guinea pig skin irradiated with Q-Switched ruby laser pulses: Morphologic and histologic findings. Arch Dermatol 1989;125:43-9.

20. Teekhasaenee C, Ritch R, Rutnin U, Leelawongs N. Ocular 1990;108:1114-20.findings in oculodermal melanocytosis. Arch Ophthalmol

21. Foulks GN, Shields MB. Glaucoma in oculodermal melanocytosis. Ann Ophthalmol 1977;9:1299-304.

22. Khawly JA, Imami N, Shields MB. Glaucoma associated with nevus of Ota. Arch Ophthalmol 1995;113:1208-9.

23. Geronemus RG. Q-switched ruby laser therapy of nevus of Ota. Arch Dermatol 1992;128:1618-22. Watanabe S, Takahashi H. Treatment of nevus of Ota with theQswitched ruby laser. N Engl J Med 1994;331:1745-50.

24. Alster TS, Williams CM. Treatment of nevus of Ota by theQ-switched Alexandrite laser. Dermatol Surg 1995;21:592-6.

25. Apfelberg DB. Argon and Q-switched Neodymium Yttrium-Aluminum-Garnet laser treatment of nevus of Ota. Ann Plast Surg 1995;35:150-3. 